\title{
Study of Nanostructured NiCrMo Base Alloy Coatings Applied via LVOF Thermal Spray
}

V. Gallegos-Orozco ${ }^{1,2}$, A. Santos-Beltrán ${ }^{2}$, M. Santos-Beltrán ${ }^{3}$, H. Morales-Rodríguez ${ }^{2}$, I. RonquilloOrnelas $^{2}$, R. Carbajal-Sanchez ${ }^{2}$, C. Modesto-Acosta ${ }^{2}$, V. Orozco-Carmona ${ }^{3}$ and M. Sánchez- Carrillo ${ }^{2}$

1. Instituto Tecnológico de Chihuahua, Ciencias Básicas, Chihuahua, Chih., México.

2. Universidad Tecnológica de Chihuahua Sur, Ingeniería en Nanotecnología, Chihuahua, Chih., México.

3. Centro de Investigación en Materiales Avanzados, Metalurgia e integridad estructural, Chihuahua, Chih., México.

The mechanical properties and corrosion behavior of nanostructured NiCrMo base alloy coatings applied via thermal sprayed by low velocity oxy-fuel (LVOF) technique was evaluated. The nanostructured powder was synthetized via high energy ball milling and used to provide sliding wear and corrosion protection for stainless steel type 316. The corrosion resistance of stainless steel samples with nanostructured coating synthesized at different milling times were evaluated. As indicated by the results, the coatings possess good corrosion resistance and mechanical properties, especially the powder fabricated first making the NiCrMo nanostructured alloy via relatively long ball-milling times and second by metallizing with $\mathrm{Al}$ powder via extra milling time. Micro hardness was used to test the nanostructured coating prepared at different milling times on stainless steel samples. The hardness was increased when incorporating nanostructured NiCrMo-Al base alloy coatings on the stainless-steel substrate. According with the results, the hardness increase is related to the nanostructured coating.

X-ray diffraction patterns of all samples are shown in Figure 1, as is noticed the patterns show a decrease of the Ni and Mo peaks after the mechanical milling process, indication the solid solution of this elements. The Fe, $\mathrm{Cr}$ and $\mathrm{W}$ elements (not detectable by the diffractometer) enter in solid solution into the Ni matrix after the milling. The increase of the peak width is an evidence of nanostructure formation during milling. The EDS Mapping images of Fig. 2a-e show a homogeneous dispersion of elements as $\mathrm{Ni}, \mathrm{Cr}, \mathrm{Mo}$, and $\mathrm{Fe}$, which corresponds to the results found on X-rays analyses. However, the $\mathrm{W}$ element is located in specific regions of the NiCrMo alloy (see Fig. 2f) meaning that not all the W content is in solid solution with the Ni matrix after $6 \mathrm{~h}$ of milling. On the other hand, in the NiCrMo nanostructured alloy with $\mathrm{Al}$ content, the $\mathrm{Al}$ element is located around the nanostructured alloy particles after the metallizing, this is appreciable on the SEM bright-field image of the mechanical milled NiCrMo-Al sample (see Fig. 3a) and in the EDS mapping image of Fig. $3 \mathrm{~b}$ for the Al element.

During the coating process of the stainless-steel type 316 surface using the thermal spray technique, the $\mathrm{Al}$ acts as binder agent in keeping the nanostructure condition in the coating. One of the main effect of the $\mathrm{Al}$ content lies in the mechanical properties of the coating. For coating produced using NiCrMo nanostructured powder coating metallized with $\mathrm{Al}$ and mechanical milled during $6 \mathrm{~h}$, the microhardness increased from $550 \mathrm{HV}$ to $750 \mathrm{HV}$. The curves of resistance to linear polarization present a good behavior of corrosion kinetic for all the samples coated with NiCrMo nanostructured alloy especially for samples with $\mathrm{Al}$ content.

References:

[1] Devicharan Chidambarama et al, Surface \& Coatings Technology 192 (2005) 278- 283

[2] Tao Kai et al, Trans. Nonferrous Met. Soc. China (2009) 1151-1160. 
[3] Vikas Chawla et al, Materials Forum volume 32 (2008)

[4] Sheng Hong et al, Materials and Design 55 (2014) 286-291

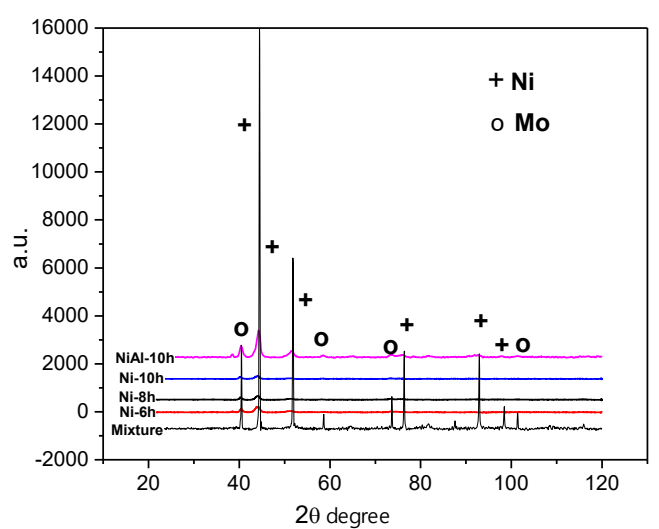

Figure 1. X-Ray diffraction patterns of the mixture NiCrMo powder and mechanical milled samples
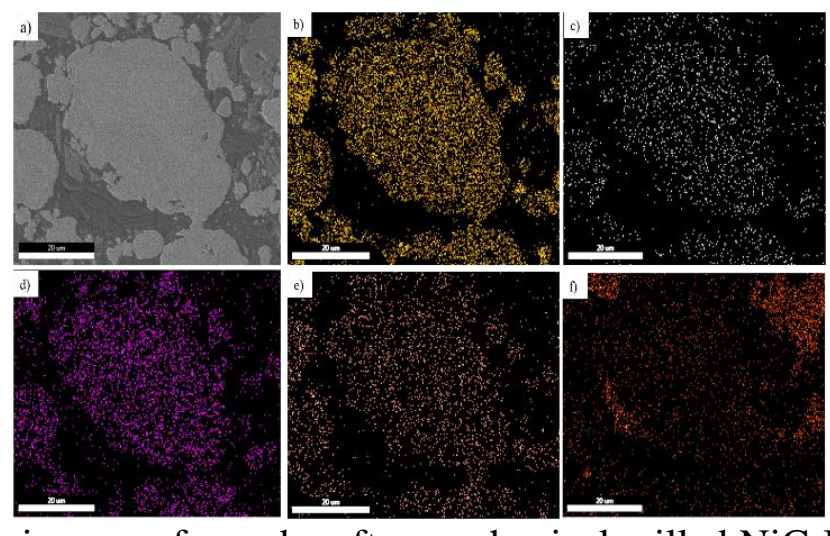

Figure 2. a) EDS Mapping images of powder after mechanical milled NiCrMo-Al sample, b) $\mathrm{Ni}$, c) $\mathrm{Cr}$, d) Mo, e) Fe and f) W element

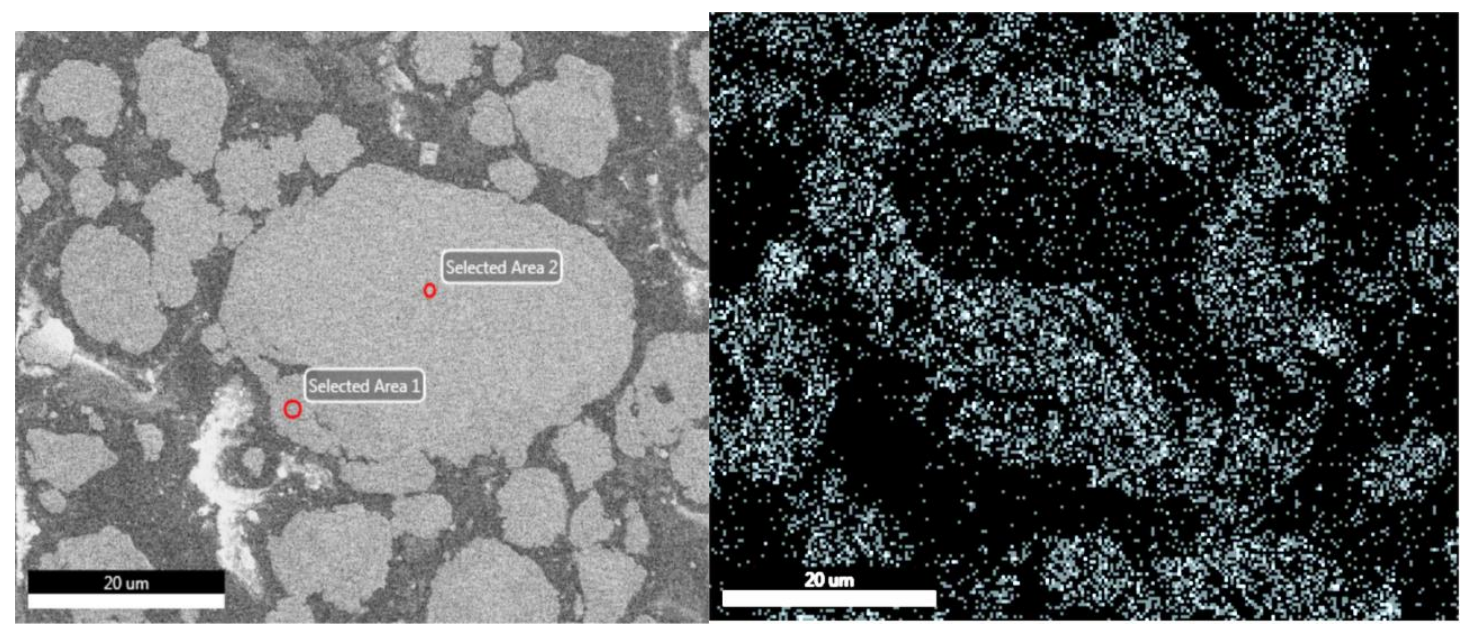

a)

b)

Figure 3. a) SEM bright-field image of the mechanical milled AlNi-6h simple, b) EDS Mapping images of $\mathrm{Al}$ element. 